\title{
Improving Health Care Waste Management in Africa: Action Research on how can Staff of Makerere University Hospital be involved in overcoming their Occupational Hazards?
}

\author{
Caleb Kusilika \\ a Faculty of Health Sciences, Uganda Martyrs' University
}

Abstract

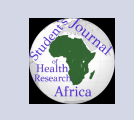

Background: ${ }^{a}$

Action research is a participatory, democratic process concerned with developing practical knowledge in the pursuit of worthwhile human purposes. In a health care setting, there are various numbers of people who go there for prevention, treatment, and care including rehabilitation. All these are vulnerable to the hazardous wastes which are generated within such a setting if not properly managed. Health care settings become more detrimental places where diseases can be transmitted and pollutants to the natural environment thus becoming harmful to the whole community at large. The research is aimed at creating both staff and clients with a conducive environment to work and live in with reduced chances of morbidity, injury, or harm occurring secondary to poor waste management.

\section{Methodology:}

This study set out to identify the health-related challenges faced by Makerere University Hospital, determine the causes of poor health care wastes management, and setting up the appropriate mitigating solutions. Data was generated using interviews for primary data and documents focused on group discussions for secondary data. Multi-voting and nominal techniques were used to identify the priority health problem. A problem and solution tree were used to provide an overview of all the known causes and effects to the identified problem and their solutions.

Results:

Most of the respondents were women $26(52 \%)$ and men were $24(48 \%)$. These were Classified into staff with clinical background $32(64 \%)$ and non-clinical staff $18(36 \%)$. Several problems were listed among which included a need to have an administrator who is medical personnel.

\section{Conclusion and recommendations:}

Poor health care waste management was the most pressing problem in Makerere University Hospital. Collaborating with the hospital community to address the poor waste management approaches, helped to improve the waste segregation, storage, transportation, and disposal in conjunction with strengthening staff empowerment that both contribute to good health living in such health settings.

\footnotetext{
${ }^{a}$ submitted: 15th/02/2021 accepted:

11th/04/2021 email: kusilika@gmail.com
}

\section{Background:}

According to Meyer (2000), Action research is a style of research rather than a specific method. The term is now identified with research in which the re- searchers work explicitly with and for people rather than research them. Its strength lies in its focus on generating solutions to practical problems and its ability to empower practitioners-getting them 
to engage with research and subsequent "development" or implementation activities. Practitioners can choose to research their practice, or an outside researcher can be engaged to help them identify problems, seek and implement practical solutions, and systematically monitor and reflect on the process and outcomes of change. Action research, as defined by Reason et al., (2001), is a participatory, democratic process concerned with developing practical knowledge in the pursuit of worthwhile human purposes, grounded in a participatory worldview which we believe is emerging at this historical moment. It seeks to bring together action and reflection, theory and practice, in participation with others, in the pursuit of practical solutions to issues of pressing concern to people, and more generally the flourishing of individual persons and their communities (Sankaran et al., 2015).

Action research is also known as participatory action research is an approach commonly used for improving conditions and practices in a health care environment (Whitelaw et al., 2003). It offers a greatly needed forum at a time of growing recognition around the world in which engagements between researchers and practitioners are central to generating both new knowledge and innovations in practice relevant to many critical problems. According to parkin (2009), Action research brings about change in a specific context and can be carried out in a health promotion setting. The action research method which is attributed to Kurt Lewin includes theoretical studies and research techniques validated by scientific communities not only aiming at knowledge but also to transform the current situation through actions that are continually problematized and evaluated.

Despite Lewin creating this method in the late 1940s, it may be said that other researchers have adopted the principles of argumentative active praxis as well as methods that combine investigation and reflective reasoning. Mobilization and action for the study have expanded the foundations of action research causing proposals for the training of professionals and contributing to the emergence of new academic approaches that action research is essential. The solution is never definitive because, in the face of a new problem, almost similar to the previous one, a new investigation should be initiated.
Action research is a form of collective selfreflective inquiry, undertaken by participants in social situations such as employees within an organization

Action Research is either research initiated to solve an immediate problem or a reflective process of progressive problem solving led by individuals working with others in teams or part of community practice to improve the way they address issues and solve problems (Helga, 2012).

Action research is particularly suited to identifying problems in clinical practice and helping develop potential solutions to improve practice. For this reason, action research is increasingly being used in health-related settings

Poor Waste management is a big problem at the moment in Makerere University Hospital and worldwide. Health care facilities generate a lot of wastes (i.e.) biomedical wastes and domestic refuse. Biomedical wastes consisting of bloody, body tissues, pus, used gloves, gauze, needles, and swabs which are highly hazardous to human health, and domestic wastes produced to less extent. In Kampala, private companies have taken up the role and services of transporting biomedical wastes to their appropriate gazetted disposal site and incineration points at a fee per kilogram of waste. Domestic waste is collected and transported by KCCA through their contracted domestic waste companies.

$39.5 \%$ of health workers experienced biological hazards while $31.5 \%$ experienced non biological hazards secondary to poor waste handling (Ndejjo et al., 2015) in Uganda. It's stipulated that $85 \%$ of the wastes generated are non-hazardous, whereas $10 \%$ are infectious and 5\% non-infectious but hazardous. Approximately 15\% to 35\% of the hospital wastes' are regulated as infectious (WHO, 2018).

If wastes generated from health care facilities are not handled with a lot of care and critical concern, then all staff working in the facilities and clients will be vulnerable to biomedical hazards like needle pricks, poor sanitary conditions, and contamination of medical equipment.

In addition to that, the surrounding community is at the stake of a poor sanitary environment originating from inappropriate waste dumping leading to major environmental problems. In the long run, all these can result in various infectious diseases to the staff, clients, and surrounding community at large. 


\section{METHODOLOGY}

\section{Study design.}

The study design was action research which involved identification of the problems, prioritizing them and finding out possible solutions to those identified problems, and then implementing them thus all done together with the community members.

This study design has been used elsewhere and has been found to work because it involved full participation of the affected community members. This design was chosen since it is result-oriented and involves community participation at all levels thus community diagnosis, prioritization, planning, implementation, monitoring, and evaluation becomes easy.

\section{Study site}

Makerere University Hospital is a private community Hospital, located on Gadaffi road just behind the Ham tower building of Wandegeya. It lies in the south of Wandegeya and just opposite Makerere University's main gate behind Ham shopping Mall Kampala district in the central region of Uganda. It was found in 1978, with one emergency department and situated approximately $1.49 \mathrm{~km}$ by road south of Mulago Hospital in Kampala capital city. Its coordinates are $0^{\circ} 19^{\prime} 40.0^{\prime \prime} \mathrm{N}, 0.3274 \mathrm{~N}, 32.5705 \mathrm{E}$. (Latitude 0.327771; longitude 32.545000). It has a capacity of 32 beds for admissions and provides both out and inpatients services to Makerere University staff and students (UBOS, 2014).

The Hospital is managed by the Director in conjunction with the Hospital Administrator and also assisted by the Senior Nursing Officer. The Hospital comprises various units which render different services to the University community. It has medical units which are available to staff both senior and junior, and students. It offers both curative and preventive services with the dental unit offering extraction, scaling, polishing, and filling in services for the teeth. There is also a new and modern x-ray unit which deals with all $x$-ray diagnosis. The laboratory concerns itself with examining samples of blood, urine, and stool.

It is a maternal and child health clinic and family planning which provides immunization services and family planning services to clients. Not forgetting the availability of 24 hours Ambulances services.

\section{Community entry}

An introductory letter was obtained from the Uganda Martyrs University to introduce the researcher to the study setting authorities. The researcher approached the office of the Hospital director from where he introduced the idea for health promotion action research and her intention to carry out a study in the Hospital. After explaining to the Medical Director the purpose and possible benefit of the study, she endorsed the researcher's letter to authorize him to continue with the study in the Hospital. The Medical director took the researcher around all departments introducing him to the respective departmental staff starting with the safe male circumcision, records department, counseling departments, and then finally wards. Also, the medical director appointed one member from each department named above whom I was to work with and all together formed a research team of five including the SMC team leader whom she delegated authority. Then the medical director handed the researcher to the SMC team leader to orient and assist the research team in the necessary help all around the hospital and throughout all departments since for her she was busy with other administrative work. The SMC team leader took the research team around the hospital community in a transect walk while the researcher was noting down what was being directly observed as health concerns. From here the research team was led to form departmental focus group discussions starting with the SMC department, records department, counseling and finalized with the Wards. The researcher used this opportunity to explain the purpose of the study to the staff in each of every department that he was taken to before forming the focus group for further discussion. The research assured the participants also to maintain confidentiality to any information given to the research team. Participation in the study was voluntary and withdrawing from the study at any time was allowed and not punishable. After explaining the study purpose and a consent form was provided to the individual, small group discussions were carried out in the lecture room together with the research team. Data was collected through focused group discussions and transect walking with observations. Participants were selected randomly from their various departments who formed the FGDs.

\section{Problem identification (community diagno-} sis). 
World Health Organization defines community diagnosis as "a quantitative and qualitative description of the health of citizens and the factors which influence their health. It identifies problems, proposes areas for improvement and stimulates action".

A research team was chosen which coordinated all the meetings; photos were taken after consenting to the photoshoot. The key informants included the Medical Director, Senior Heads of departments, and other members of the University Management Committee. The reason why these were chosen as key informants was because all of them have served the hospital for a long that has even led them to obtain the most senior positions. This implies that they are well versed with most of the knowledge that pertains to the Hospital across all aspects of operations and the most challenges faced by the hospital.

Data were collected from focus group discussions and observations. The researcher conducted small focus group discussions using clear guiding questions after obtaining consent to participate in the study. Information was recorded, compiled, and transcribed for easy analysis. Tools used include paper, pens, and asking the participants to write the problems on paper. The most preferred were focus group discussions and direct observations.

Focus groups are forms of group interviews that capitalize on communication between research participants to generate data.

\section{Problem prioritization}

Before implementation of prioritization, preliminary preparations were carried out to ensure that the most appropriate and urgent health issues are selected to be addressed. The assessment was carried out, clarification of objectives and processes, and the establishment of appropriate criteria which judge the merit of potential focus areas was important to avoid selection bias. When prioritizing the problem the following criteria were considered; Impact of the problem, availability of solution, resources to solve the problem, and the cost involved.

The multi-voting technique was used where a long list of health problems was narrowed down to get a health problem that may be a health priority that is affected by most of all. The mechanism of prioritizing health problems through group input known as the nominal group technique was also used in conjunction with multi voting technique.

\section{Problem analysis}

Data analysis was based on the study objectives and research questions. Qualitative data provides rich descriptions and explanations that demonstrate the systematic flow of events as well as often leading to chance findings. The statements of all the participants were recorded on paper and the questionnaires were transcribed by the researcher. The transcribed notes were coded by topical areas reflective of the general questions provided earlier. Through the open coding method (Glaser \& Strauss, 1967) the topics were identified, named, and categorize. The transcriptions were examined to discover any particular patterns or themes within the interviewee's views displayed through their answers.

The raw data was analyzed and themes were created based on the participants' answers and examined closely to determine whether answers to the research questions could be captured within the raw data. Different themes were then created relative to the analyzed raw data and through this process, the data was explored by the researcher and the interpretations were developed. All the data was collected, and then checked for consistency and entered into a datasheet, and analyzed on the computer.

A problem tree was used to provide an overview of all the known causes and effects to the identified problem and context in which an intervention was to occur and reveal the complexity of life. The researcher, the team, and the hospital staff identified the causes and the effect and developed a solution tree. The solution tree was developed by reversing the negative state which helped the team to select and focus on intervention of the preferred strategy.

\section{Sampling frame and Sampling procedure.}

A register book for the daily attendance of all staff in the Hospital was used with equal chances given to all staff who feels free, willing, and convenient to participate in the research. This is done by going through all hospital departments to obtain an informed consent

\section{Quality control \\ Validity}

Validity refers to the extent to which a measurement procedure measures what is intended to measure. Validity was ensured through methodology triangulation that combined both conversations 
and structured results that support them. FGD guidelines were carefully designed to have them easily and clearly understood by both the interviewer and the respondents. In so doing, it helped to capture only the intended information.

\section{Reliability}

Reliability refers to the dependability of the measuring instrument. It measures the degree to which a research instrument yields consistent results or data after repeated trials (mugenda and mugenda, 2003). It was achieved by pre-testing the research tools, checklist in different or similar settings and comparing the results before the tool is eventually used to collect data in the real research area.

\section{Ethical consideration}

Permission to do the study was obtained from Uganda Martyrs University and then from the Medical Director, and other following heads of departments. Voluntary informed signed consent was obtained from the study participants and information obtained was handled with the high level of confidentiality and participants were signed a number each to avoid using their direct names in addition to participants being at liberty to withdraw their involvement in the study

\section{The Intervention Or Innovation}

The facility proposed to dig a pit for the burning of the wastes, conduct health education to raise awareness of the staff, and write to the University Management authority and board for procurement of personal protective equipment for the waste handlers, supply of bins and bin liners.

It includes research question(s)/implementation objectives, plan of action, and time frame of the implementation of intervention/innovation.

The health-related problems faced by Makerere University Hospital have been identified already and as Objectives modified to address the problems according to the locally proposed solutions by the hospital community.

\section{Health-related problems at the Hospital}

Working with the research team and the entire staff, a list of health-related problems was generated and inappropriate medical waste management was prioritized as the one which required argent attention before it affects the majority of them. The team suggested different solutions at all levels of poor medical waste management as below.

Generation.
Together with the research team and the management of the Hospital, healthcare workers were to be oriented on the pertinent issues concerning medical waste segregation. The types of wastes and their common sites of generation within the facility were identified. Waste handlers particularly were cautioned with emphasis on the potential risk of harm (infections) that they may encounter while handling medical wastes.

\section{Segregation.}

Healthcare workers were to be sensitized on the principles of waste segregation. The separation of the different types of wastes was to be restated appropriately. This was done by use of a job aid/standard operating procedures tool which specified the type of wastes to be placed in the different colors coded waste bins and to ensure that all sharps are put into safety boxes.

\section{Storage.}

The research team together with the waste handlers shall identify sites for the temporary storage of wastes within the hospital premises. There shall be one of the waste handlers in charge of general duties in this hospital was the one to open this place and lock to ensure that waste was safely kept there without being dispersed around. The waste handlers shall collect wastes every morning and keep them at the temporary storage site. It's from this site that transporting companies will come to weigh them to estimate the average quantity and amount to be paid and then transport them to the disposal site.

\section{Transportation.}

From the sites of generation, wastes are always carried by the waste handlers using their hands and heavy-duty gloves in their collected dust bins to the storage site. From this storage site, wastes shall be collected and transported by collecting companies that dispose of them off to the final disposal site. Biomedical hazardous wastes have always been collected by privately hired companies as advised by Kampala City Council Authority while domestic refuse will be collected by K.C.C. Itself through their hired domestic waste companies.

\section{Disposal.}

The hospital lacked a standard incinerator hence it opted to hire private collecting companies to transport the wastes to the recommended incineration sites and disposal areas. They also agreed to secure the pit with a locally made fence.

\section{Theory of change}




\begin{tabular}{ll}
\hline Main problem & Solutions \\
The main problem was & $\bullet$ Continuous training and CMEs on waste management approaches • Appoint focal \\
poor waste & person for waste management within the hospital to ensure that wastes generated \\
management in the & are properly sorted and disposed off • Waste collection site allocation • Ensuring \\
Hospital & adequate supply of dustbin, biohazard bag, to ensure maximum segregation of \\
& wastes generated at the hospital. • Contracting waste collecting companies both \\
& domestic and bio hazardous waste collecting companies • Regular meetings held \\
& to evaluate more on progress and address identified gaps
\end{tabular}

\section{Theory of change;}

Theory of change is an outcome-based approach which applies critical thinking to the design, implementation, and evaluation of initiatives and program intended to support change in their context. In this case, the Health Belief Model was employed which illustrates that change in a person's behavior is dependent on the extent to which they perceive themselves susceptible, perceived severity, perceived benefits, perceived threat, then modifying factors. If they perceive the behavior to have more harm or risk and expect to benefit if they change then change will occur gradually within them and their communities and vice versa.

\section{1}

\subsubsection{Explanation and application of theory of change}

The long term goal is to prevent health problems that occur in the hospital secondary poor waste management. In order to achieve this, the following conditions are required;

Identify the interventions that the initiatives will perform to create these outcomes

\subsection{Plan of action}

Makerere university hospital faces several health related problems but here is the most significant identified problem with proposed solutions by the community.

\section{Action plan for implementation of the inter- vention \\ Time frame for the project}

The time frame means the specific duration or period in which a certain activity is to take place in this case the implementation of the interventions proposed by the community. The agreed period of time was six months 2 nd Jan to 30th June 2018. 5.5 Time frame of the implementation of intervention/innovation

\subsubsection{Table 3: showing time schedule for implementation.}

\subsection{Monitoring and Evaluation}

Monthly monitoring and evaluation was conducted in order to track the progress of the interventions implemented whether they were effectively being done according to the set objectives. Continuous quality improvement sessions were conducted in order to revise the objectives and strategies to achieve the stipulated goal in areas were gaps were identified.

\subsubsection{Table 4: showing the monitoring and evaluation plan of the project Reliability and validity \\ Reliability}

Reliability being a measure of the degree to which a research instrument yields consistent results when used in repeated trials. The pilot study which was conducted helped me in assessing the clarity of the questions to be asked and discussed. Any phrases that were not clearly understood were modified accordingly. This was done to improve the quality of information that is gotten hence improving the reliability of the data collected.

\section{Validity}

Validity is the accuracy and meaningfulness of inferences, which are based on the research results. The pilot study helps to improve the face validity of content which can be improved through expert judgment hence the assistance that was acquired from supervisors who are research experts helped me a lot in improving the validity of the content.

\section{Lessons learnt / self-evaluation}

For any project, prior planning is fundamental for its success accompanied by thorough Implementation, monitoring, and evaluation of projects following the set objectives.

All community-related projects require teamwork which is easily achieved through ensuring commu- 
Table 1. Explanation and application of theory of change

\begin{tabular}{ll}
\hline $\begin{array}{l}\text { ELEMENTS OF THEORY OF } \\
\text { HEALTH BELIF MODEL } \\
\text { perceived susceptibility }\end{array}$ & $\begin{array}{l}\text { DESCRIPTION/EXPLANATION } \\
\text { During a self-reflection on the problem one asks himself whether they are } \\
\text { perceived severity }\end{array}$ \\
$\begin{array}{l}\text { Personal refection on the magnitude of harm in chance of failure to change } \\
\text { the bad behavior } \\
\text { perceived benefit }\end{array}$ & $\begin{array}{l}\text { not change and vice versa } \\
\text { the overall degree consequence associated to failure to change } \\
\text { perceived threat }\end{array}$ \\
Modification & $\begin{array}{l}\text { Surrounding environment, politics and a stake holders interests dictates the } \\
\text { rate of change in the community and whether to change or not }\end{array}$ \\
\hline
\end{tabular}

Table 2. Action plan for implementation of the intervention

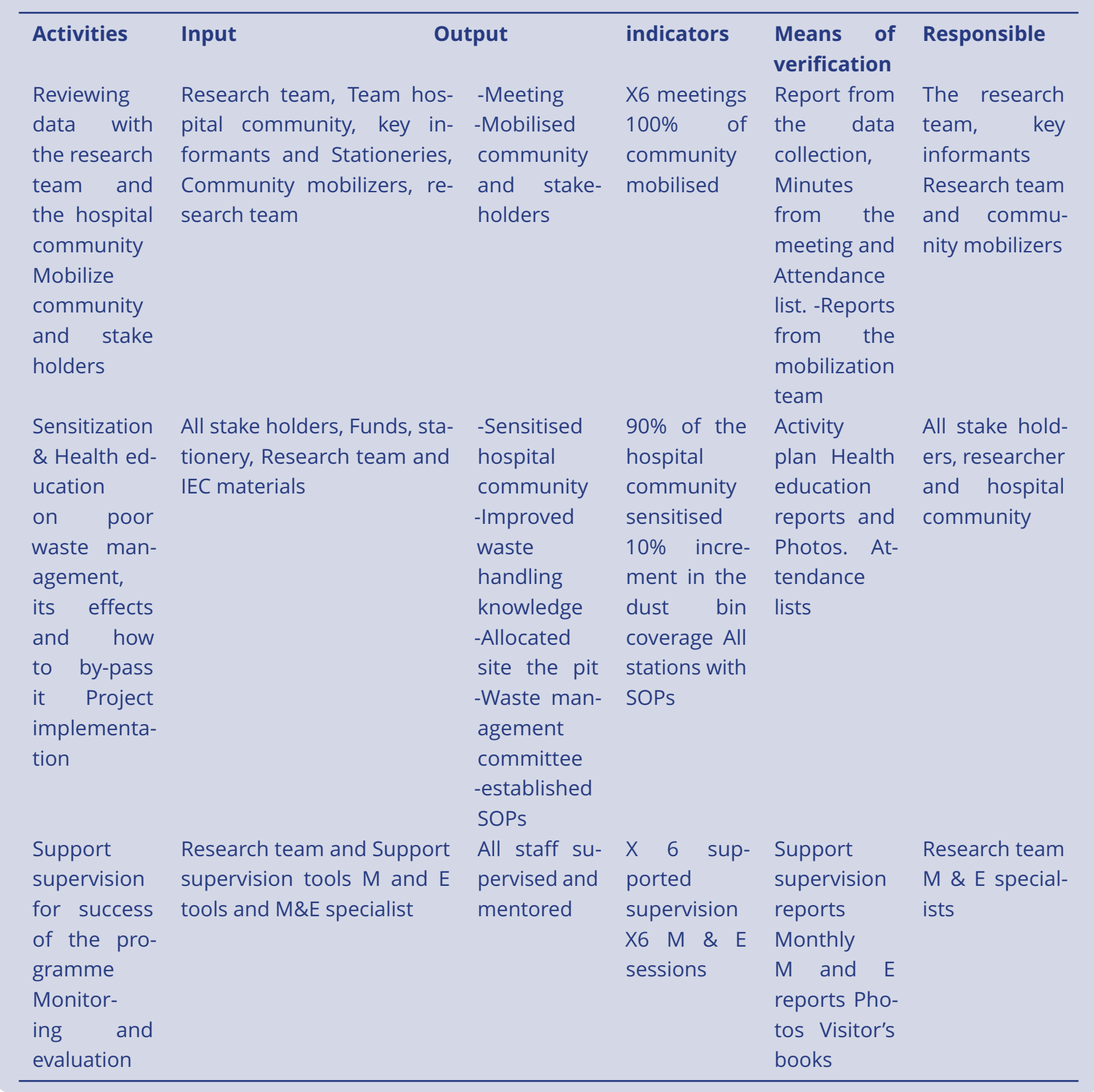


Table 3. Showing time schedule for implementation

\begin{tabular}{|c|c|}
\hline MONTHS & ACTIVITIES \\
\hline $2^{\text {nd }}$ JAN 2018 & $\begin{array}{l}\text { Meeting the research team, Team from the hospital community, to review data with the } \\
\text { research team and the hospital community members, end of Jan M\&E session. }\end{array}$ \\
\hline $1^{s t}$ FEB 2018 & Community mobilization and sensitisation plus M\&E \\
\hline $1^{s t} \mathrm{MARCH}-$ & Pre implementation meeting \& Implementation of the project, $M \& E$ \\
\hline \multicolumn{2}{|l|}{$30^{\text {th }}$ APRIL } \\
\hline \multicolumn{2}{|l|}{2018} \\
\hline $1^{s t}$ MAY 2018 & Support supervision on-going, M\&E \\
\hline $1^{\text {st }}$ JUNE 2018 & End of Project Monitoring and evaluation. \\
\hline
\end{tabular}

Table 4. showing the monitoring and evaluation plan of the project

\begin{tabular}{|c|c|c|c|c|}
\hline $\begin{array}{l}\text { Hier- } \\
\text { ar- } \\
\text { chy } \\
\text { of } \\
\text { aims }\end{array}$ & Objectivity & Verifiable indicators & $\begin{array}{l}\text { Means of } \\
\text { verification }\end{array}$ & Assumption \\
\hline Goal & $\begin{array}{l}\text {-To improve the health status of } \\
\text { Makerere university Hospital through } \\
\text { proper waste management. }\end{array}$ & $\begin{array}{l}\text { Reduced number of } \\
\text { health related } \\
\text { problems due to } \\
\text { inappropriate waste } \\
\text { dumping. }\end{array}$ & -Reports & $\begin{array}{l}\text { Hospital Wastes } \\
\text { are properly } \\
\text { managed }\end{array}$ \\
\hline $\begin{array}{l}\text { Ex- } \\
\text { pected } \\
\text { Out- } \\
\text { come }\end{array}$ & $\begin{array}{l}\text {-Reduced number of health related } \\
\text { problems due to well sensitized } \\
\text { community. }\end{array}$ & $\begin{array}{l}\text { Reduced number of } \\
\text { health related } \\
\text { problems. }\end{array}$ & $\begin{array}{l}\text {-Reports - } \\
\text { reduced } \\
\text { number of } \\
\text { occupational } \\
\text { hazards }\end{array}$ & $\begin{array}{l}\text { Hospital Wastes } \\
\text { are } \\
\text { appropriately } \\
\text { handled and } \\
\text { managed. }\end{array}$ \\
\hline $\begin{array}{l}\text { Out- } \\
\text { put }\end{array}$ & $\begin{array}{l}\text {-Team working spirit -SOPs established } \\
\text { all in @ department -Allocated site for } \\
\text { rubbish pit -Sensitized staff -established } \\
\text { waste management committee }\end{array}$ & $\begin{array}{l}\text {-Improved sanitation } \\
\text {-Number of staff } \\
\text { sensitised -Adequate } \\
\text { \& timely supplies }\end{array}$ & $\begin{array}{l}\text {-Photos } \\
\text {-Attendance } \\
\text { list -receipts } \\
\text {-evaluation } \\
\text { tests }\end{array}$ & $\begin{array}{l}\text {-All staff } \\
\text { sensitised in the } \\
\text { trainings }\end{array}$ \\
\hline $\begin{array}{l}\text { In- } \\
\text { puts } \\
\& \\
\text { Activ- } \\
\text { ities }\end{array}$ & $\begin{array}{l}\text { Meetings, mobilization, sensitization, } \\
\text { implementation, posting SOPs, } \\
\text { stationery, finances, staff to be } \\
\text { sensitised }\end{array}$ & $\begin{array}{l}\text {-Number of meeting } \\
\text {-number of trainings }\end{array}$ & $\begin{array}{l}\text {-Minute of } \\
\text { meetings, - } \\
\text { photos } \\
\text {-Receipts }\end{array}$ & $\begin{array}{l}\text {-Well mobilized } \\
\text { community. } \\
\text {-Meetings } \\
\text { carried out as } \\
\text { planned }\end{array}$ \\
\hline
\end{tabular}

nity participation and involvement in all interventional affairs from planning to evaluation as this ensures sustainability.

Behavioral change is not an instant thing to occur however we should learn to appreciate differences and be patient for each other to effect change since it's a long process (Trans-theoretical theory).

\section{Implementation Of Action Plan}

Implementation process

Stage 1- Initiation phase
The leadership team was examined to guide in the exploration, this included the medical director, hospital administrator, heads of the department research team, and the researcher. The team together carried out a needs assessment and system analysis to explore the feasibility of the innovation. The implementation process was reviewed to evaluate the effectiveness of the activities to be carried out. This helped to evaluate if the intervention achieved its purpose for which it was designed and 
the team agreed to move on with the plan to purchase a tank as discussed as one of the solutions.

\section{Stage 2-Planning /installation stage}

The research team conducted a planning meeting where they established the objectives of the project, formulated policies for implementation strategies, each member is given responsibility, and resources were allocated. The team also called for participation through a communication plan from the hospital community to help ensure that what had been agreed upon was being implemented.

\subsubsection{Table 5: Communication plan}

The communication plan was developed to help address the needs of the study. It aimed at promoting and improving health of Makerere university Hospital with a specific objectives of finding out the causes of poor waste management, the effects of poor waste management, and what can be mitigate/ overcome this problem.

Key message. Improving health of Makerere university hospital through appropriate waste management as proper sanitation improves lives.

\subsubsection{Table 6: showing Swot analysis \\ 2.4 Theoretical model for the communication plans}

The Health belief model of behavior change was used during the study to make messages that will enable behavior change. This model assesses an individual's readiness to act on a new healthier behavior depending on his perception of changing the behavior. Perceived susceptibility one reflects on himself whether is predisposed to the problem, perceived severity in this stage there is the imagination of the degree of seriousness and complexity of the problem, perceived benefit in which one looks out for whether there is a reward for changing and finally modifying factors which are the surrounding environment to keep him empowered to that change made.

\section{Stage 3- implementation}

The research team gathered before actual implementation; to finalize with the actual site where the temporary storage of wastes was to be established. They proposed a single room just beside the SMC department which was previously used as a kitchen and agreed to make some small modifications and a lockable system. Since there were more health workers, they were knowledgeable about waste handling but only claimed to have had more shortages with what to use. It's for this matter that the hospital management, through the medical director pledged to adequately and timely fund the project's activities through procurement of supplies and equipment required. She further cautioned the focal person and all heads of departments to critically follow up the standard operating procedures for waste management in their areas of operations as they will have no other excuse.

The site implementation team ensured support with the medical director and communicating to the rest of the staff in the hospital community about the new development and the research team carried out a sensitization and health talk program about the effects of poor health care waste management, occupation hazards and general hygiene and sanitation. Adequate biohazard bags, bins, PPEs like heavy gloves, gumboots, and gaggles were all stocked at the hospital store within a week. This was meant to ease segregation, storage, and transportation of wastes in the Hospital. Now the is the temporary storage of waste in the hospital from which the hired biohazardous company collects them.

\section{Stage 4-Outcome}

There is now an improved wastes handling system that has improved sanitation in the hospital. The hospital community is now aware of the effects of poor waste handling hence more sensitized. There is also a marked reduction in reported occupational hazards originating from poor waste handling like needle pricks. All waste handlers have enough PPEs to at least keep sanitation through proper waste handling strategies within the hospital.

\section{Sustainability Plan/Strategy}

The sustainability of the outcomes from the implemented project was ensured through the following strategies for better living conditions in this hospital setting right from the beginning of the project up to the end.

1) Community participation and involvement of all the community members in all steps of the project right from community diagnosis, prioritization, and mobilization of resources, implementation, monitoring, and evaluation of the project performance promoted ownership which is a key factor for maintained use of the established interventions.

2) Involvement of the hospital management which empowered them to mobilize resources to 
Table 5. Communication plan

\begin{tabular}{|c|c|c|c|c|}
\hline Description & Type & $\begin{array}{l}\text { Audi- } \\
\text { ence }\end{array}$ & Delivery method & $\begin{array}{l}\text { Fre- Responsible person } \\
\text { quency }\end{array}$ \\
\hline Status report & $\begin{array}{l}\text { Manda- } \\
\text { tory }\end{array}$ & $\begin{array}{l}\text { Hospital } \\
\text { commu- } \\
\text { nity }\end{array}$ & $\begin{array}{l}\text { Report to audience through } \\
\text { regular evaluation meeting, } \\
\text { Notice board report }\end{array}$ & $\begin{array}{l}\text { MonthlyMedical director, hospital } \\
\text { administrator, member of } \\
\text { research team }\end{array}$ \\
\hline $\begin{array}{l}\text { Local awareness } \\
\text { information of } \\
\text { project. }\end{array}$ & $\begin{array}{l}\text { Infor- } \\
\text { ma- } \\
\text { tional }\end{array}$ & $\begin{array}{l}\text { Hospital } \\
\text { commu- } \\
\text { nity }\end{array}$ & $\begin{array}{l}\text { On the Notice board for } \\
\text { everyone to see it. }\end{array}$ & $\begin{array}{l}\text { MonthlyResearch team and the } \\
\text { hospital administrator }\end{array}$ \\
\hline
\end{tabular}

Table 6. showing Swot analysis

Strength - Support from senior management team like the medical director. $\bullet$ Willingness and commitment of the hospital community members to participate in the study and create change.

Opportunities - CMEs were used as sensitisation platforms • Hospital community was already classified into departments • Health workers were knowledgeable about the waste management approaches.
Weakness • Limited time for interaction with staff and health education $\bullet$ Lack of enough funds to effect all the suggested solutions

Threats • Some staff were requesting for money to participate. - There a lot of bureaucracy issues use in solving the health challenges in their hospital and enforcing them.

3) Use of locally available resources in the hospital helped members to appreciate their problems and knowing that solutions lie within their community.

4) Reflection of the intervention.

The whole project involved consultations and active participation of hospital management, heads of departments, and the general staff in the planned activities. The involvement of the hospital management in the research at different levels of planning got them concerned with the findings from their community and hence became more interested in implementing the designed strategies to improve the health status in the hospital urgently.

A well-trained and dedicated team is a very paramount factor to consider during any implementation of a new project. This was because it's faced with various challenges like financing, human resource, lack of commitment, and follow-up. All these are never sufficient and it involves sacrifice especially when it comes to a government institution. However, it was of help to me given the fact that Makerere University is a financially independent entity and an institution of high reputation they quickly intervened.
Clarifying roles and responsibilities is a crucial element in project implementation. Careful attention should be given to who does what when, where, and how. Managerial supervision and involvement is an essential factor as well as recognizing the role of residents and information sharing. The researcher learned that research is a knowledge and learning tool which contributes to improved service delivery; studies. It is very important to explore the aim that the research is to achieve to be successful. Establishing a functional system in the implementation of every project is an influential deal because it ensures sustainability and continuity of workflow.

Lastly, the researcher also learned that Communities always know their problems and they have ideas of what can be done to address them. They therefore only require stimulation and empowerment of the communities to proactively address their health challenges to improve their health outcome which this study aimed to achieve.

\section{Dissemination of findings.}

Upon completion of the research report copies will be disseminated to the research and ethics committee of Uganda Martyrs University, a copy to the research committee of K.C.C.A and a copy to the administration of Makerere University Hospital. 


\section{Results of community}

\section{diagnosis.}

Findings based on direct observations and FGDs in community diagnosis.

Community diagnosis is a process of finding out the community's problems which could be health or health-related in particular groups of people living together to prioritize and finding out the appropriate interventions to mitigate them.

Below are the results presented according to the answers given by the staff to the questions in focus group discussions.

\section{1}

\subsubsection{Table 7. Distribution of} Respondents by department.

Most of the respondents were women 26(52\%) and men were $24(48 \%)$. Classified staff in clinical background contributed more participating portion $32(64 \%)$ to non-clinical staff $18(36 \%)$. This was because the clinical staffs were more willing to participate freely in affairs affecting them and were more knowledgeable than the non-clinical staff.

\subsubsection{Table 8. Specific department:}

\section{Generated list of health problems}

a. Poor waste disposal especially biohazardous wastes, food (leftovers), and plastic bottles.

b. Sharing of one toilet with staff and clients both men and women e.g you find you have a diarrheal disease client onward using the same toilet with others.

c. Lack of sufficient equipment to use in the hospital cleaning like gloves, jik, heavy-duty gloves, use and re-use of $\frac{3}{4}$ filled safety boxes, aprons, gumboots, soap, stethoscope, blood pressure machine, etc.

d. Lack of isolation units for highly infectious diseases like diarrheal diseases, TB yet by then there were found to have TB client undergoing treatment being monitored by Mulago Hospital. But these staff did not even have the TB protective Masks etc.

e. Complaining also of the old bedsheets, blankets which some had tears, no pillows causing even big shame to the staff providing to a client for use. This tone linen is said to have been brought in the year 2000 up-to-date.

f. Lack of breakfast and lunch yet they are overwhelmed by a lot of work. g. Work overload that is to say a nurse goes ahead to do the doctors' work, dispensing, etc.

h. Apart from drinking water in the SMC department, other departments had no drinking water sources or dispensers. Therefore both staff and clients had to keep buying or taking unsafe water. And however much there is a dispenser with drinking water at the SMC departments, it was only meant for Post operated SMC clients but staffs just encroach on it.

i. Use of smoky lanterns which are only two hence not even enough on the ward wing when power has gone.

j. Lack of training opportunities, conferences, CMEs to help them to be up-to-date with health knowledge and new interventions.

k. Lack of medical insurance to the staff and their families.

I. Need for Hospital Administrator who is medical personnel, claiming that the administrator who has no medical knowledge takes long to answer staff urgent queries accompanied by asking them irrelevant questions like "Naye jik mumunywabunywu oba?" meaning are you just drinking the jik I supply to you for use or? That happens when you ask for jik for disinfection around the hospital.

\section{Transect walk}

Wards were found to have such open and old mattresses, torn bedsheets, blankets, No supply of drinking water, inappropriately scattered \& dumped wastes all around, Absence of SOPs, Dusty window rovers, Safety boxes were already $\frac{3}{4}$ full, one toilet being used for both men and women, unsafe site for temporary waste storage, dismantled incineration station.

\section{Focus Group Discussion.}

This was carried out on a department-based level with the help of the research team. We discussed all the health-related problems in the hospital from the wards, SMC, records, counseling, and chambers of the cleaners. With the help of the research team and the staff involved in every FGD for solving some of the problems, we were able to prioritize the staffs' health and health-related problems based on the Majority visit the minority in the nominal counting of the respondents support. Focus groups are a form of group interview that capitalizes on communication between research participants to generate data (kit zinger, 1994). Focus Group discussion of a questionnaire is ideal for 
Table 7. Distribution of Respondents by department.

\begin{tabular}{llll}
\hline Department & Men & Women & Percentage distribution \\
Clinical staff & 12 & 20 & $64 \%$ \\
Non clinical staff & 12 & 06 & $36 \%$ \\
TOTAL & 24 & 26 & $100 \%$ \\
\hline
\end{tabular}

Table 8. Specific department

\begin{tabular}{llll}
\hline Department & Men & Women & Percentage distribution \\
S.M.C & 12 & 16 & 56 \\
Cleaners & 02 & 04 & 12 \\
Wards & 00 & 04 & 08 \\
Records department & 06 & 00 & 12 \\
Counseling & 04 & 02 & 12 \\
TOTAL & 24 & 26 & 100 \\
\hline
\end{tabular}

testing the phrasing of questions and is also useful in explaining or exploring survey results.

During the transect walk, we observed many health and health-related challenges in their hospital compound and wards. The staff noted all they had observed and perceived as major health problems to have them discussed upon in their respective FGD sessions.

In the SMC department these health problems were discussed as follows;

There is indiscriminate waste disposal especially biohazardous wastes, leftover foods, and plastic bottles are becoming rampant. We request the hospital to procure sufficient supplies like dustbins and bin liners in conjunction with the use of SOPs.

Sharing one toilet with staff and clients both men and women is not healthy because one may have a particular infectious disease that can easily be transmitted to all staff and clients. She further stressed that it would be better to separate staff toilets from client toilets and also males having their own different from that of the females.

There is a tendency of using and re-using safety boxes which already are $\frac{3}{4}$ filled of which these safety boxes are soft to allow needles to penetrate through. This has been one of the most causes of needle pricks to our fellow staff due to protruding needles. Safety boxes bought should be of a high standard and should never be re-used to avoid occupational needle prick hazards.

We lack sufficient PPEs to use in the hospital cleaning like heavy-duty gloves, aprons, gumboots, and gaggles. We request the hospital to procure enough supplies and PPEs such that staff can have no excuse for poor waste dumping.

In the FGD on the wards, these health problems were said,

1. We lack breakfast and lunch yet we are overwhelmed by a lot of work where a nurse goes ahead to do the doctor's work. We request that the hospital management provide us with lunch and establishing systematic scheduled shifts of staff.

2. We Lack isolation units for highly infectious diseases like diarrheal diseases and TB clients even now there is one undergoing TB treatment being monitored by Mulago Hospital but staff do not even have the TB protective Masks. We request that the hospital establishes isolation units for such conditions.

3. We have old bedsheets and blankets which are torn and lack pillows even ourselves giving them to our clients we feel ashamed of the quality of linen we are giving to them. This linen was brought in the year 2000 up-to-date. We request that the hospital management buy new linen for its esteem clients.

4. We lack drinking water so staff and clients keep taking unsafe water and however much there is a dispenser with drinking water at the SMC departments, it is only meant for Post operated SMC clients but staff just encroaches on it. We request safe drinking water for both staff and clients.

5. We use smoky lanterns which are only two hence not even enough on the ward wing when power has gone, Lack of training opportunities, con- 
ferences, CMEs to help them to be up-to-date with health knowledge and new interventions, Lack of medical insurance to the staff and their families.

\section{In the records department, staff said that,}

There are inappropriate waste disposal and dumping, Lack of breakfast and lunch, Work overload, dusty window rovers, lack of insurance, and low and delayed salary payments. They further proposed regular dump dusting, work shifts, advocacy for salary increment, and lunch provision.

\section{In the cleaners department staff said,}

We lack enough PPEs, staff negligence to follow set up SOPs and also to use dustbins and bean liners inappropriately, medical personnel to work as a hospital administrator. There is a need to keep training staff to keep them updated on new standard waste management approaches and utilization of SOPs.

\section{In the counseling department staff said,}

We receive very little payments which even come at a delayed time, lack insurance policies, inappropriate wastes littered all around. We request welldistributed dustbins around advocate for insurance policies and salary increment.

Because of a busy schedule, I could only have a limited time to gather them into such FGDs which was at lunchtime and after work at 5:00 pm so each day I could handle one FGD. Below is a list of all health and health-related problems generalized from all departmental focus group discussions.

\section{How were the problems prioritized?}

This was done by considering the Majority of the respondents voting by choice during each FGD with the help of the research team. It's from this that most respondents were in strong support of all those problems that have been transcribed and ranked in first, second, and third positions as they had the majority of the votes in total from all the departments. The following were the solutions that were proposed to be implemented to improve the poor waste management approaches within the hospital;

\subsubsection{Table 9. How the challenges were prioritized according to need.}

Prioritized health challenges according to the number of votes gotten.

\section{Proposed Solutions}

i. Advocating for a continuous supply of adequate equipment and sundries like rubbish pits ii. Daily damp dusting and disinfection around everyone's places of work.

iii. Adequate supply and proper use of protective gears.

iv. Proper dust bin alignments and allocations at different points of work.

v. Advocate for separation of toilets for the clients, men, and women from those of staff.

vi. Advocate for isolation units (wards) for highly infectious patients.

vii. Provision of updated health education and information through CMEs, training, seminars, and conferences on waste management.

viii. Opening up a good gazette site for dumping wastes from the hospital from which they will be burnt or they can be collected from by the collecting companies for proper disposal (rubbish pit).

\section{Conclusion.}

Basing on the findings of the study, there is still a gap to bridge if we are to sustainably improve the health of the staff working within Makerere University Hospital. This was evidenced by the overwhelming number of health and health-related problems they raised.

The idea of health promotion is highly valued in different communities only that it has just been lacking manual personnel to sell it and enable facilitation but as long this is fulfilled it's bound to yield positive results.

\section{Reflection on chapter three}

After prioritization of poor waste management as the most pressing health problem among others, it was noted that this has diverse negative consequences to human health. Inappropriate wastes dumping results in poor sanitation and harbors fly. Most of this waste is body parts related like bloody gauze, swabs which predispose humans to infectious hazards secondary to such waste.

However, given the hospital community involvement and participation in the interventions to address their problems, it is assumed that the is going to be a smooth and tremendous change observed within the hospital. This is attributed to the spirit of community empowerment attained to demand their services and manage their locally affordable health-promoting interventions. 
Table 9. How the challenges were prioritized according to need.

\begin{tabular}{|c|c|c|c|c|c|c|c|}
\hline Health problems & SMC & Wards & Records & $\begin{array}{l}\text { Counsel- } \\
\text { ing }\end{array}$ & clears & $\begin{array}{l}\text { to- } \\
\text { tal }\end{array}$ & $\begin{array}{l}\text { prior- } \\
\text { ity }\end{array}$ \\
\hline lack of breakfast or lunch & 4 & 3 & 3 & 5 & 1 & 15 & 3 \\
\hline $\begin{array}{l}\text { Lack of isolation units for highly infectious } \\
\text { diseases }\end{array}$ & 4 & 7 & 4 & 4 & 0 & 19 & 2 \\
\hline Poor bath room and toilet maintenance & 5 & 6 & 1 & 0 & & 12 & 5 \\
\hline low and delayed salary payments & 6 & 4 & 1 & 2 & 1 & 13 & 4 \\
\hline lack of protective gears & 5 & 4 & 1 & 2 & 1 & 12 & 5 \\
\hline $\begin{array}{l}\text { Inappropriate dumping and scattering of } \\
\text { wastes }\end{array}$ & 8 & 4 & 6 & 5 & 0 & 23 & 1 \\
\hline Lack of updated trainings through seminars & 2 & 3 & 0 & 2 & 0 & 7 & 7 \\
\hline Occupational hazards, needle pricks & 3 & 1 & 1 & 0 & & 5 & 9 \\
\hline Dusty window rovers & 2 & 1 & 3 & 1 & & 7 & 7 \\
\hline Lack of medical insurance & 2 & 4 & 1 & 1 & 1 & 8 & 6 \\
\hline $\begin{array}{l}\text { Use of smoky lanterns on wards when power } \\
\text { goes off. }\end{array}$ & 0 & 6 & 0 & 0 & 0 & 6 & 8 \\
\hline
\end{tabular}

\section{Discussion Of}

\section{Implementation Results Summary of information generated Community involvement and Participation}

During the implementation project, it was noted from the beginning of the project that its success depended on the acceptability of the community to recognize that there lay health challenges in their community and thus the need to address them. The community knew their problem better and they only needed to be facilitated and empowered to identify and redress them using their resources. This is in line with the principle of primary health care of Community participation which entails involving all community members in promoting health and addressing health problems at the community level which enables the community to take ownership for the health and wellness of its people.

\section{Community mobilization and Leadership}

Community mobilization was achieved through the use of the hospital management and this indicated that every community has its leadership structure which must be followed right from community entry if the project is to be accepted and sustained. This, therefore, confirmed the notion that leadership structure in a community determines the acceptability of a program to be implemented in a setting since what is regarded as right will be easily adopted by their subjects.

Resources for the project
Hospital leadership was able to mobilize resources for the implementation of the project and this meant that resources to address most health community problems lie within the community, they only require to be mobilized and empowered to use their local resources to address their health challenges. Through this, the use of appropriate technology is achieved which is adaptable to the local needs and acceptable to be applied.

\section{Working with other stakeholders}

Some community problems require working with other agencies to address them. In this project, it was realized that effective waste management in the hospital required collaborating with private biohazardous companies and KCCA hired companies for domestic waste collection. Thus the principle of inter-sectoral collaboration is vital if we are to achieve and improve the health of the community.

\section{Sustainability plans}

Sustainability is the continuation and maintenance of structures or initiatives created or benefits of inputs distributed beyond the lifetime of the project to achieve a wider and long-term impact (ACF-IN 2007). To ensure the sustainability of the interventions started, the following strategies have been put in place;

\section{1}

5.1.1 Table 10: showing sustainability plan 
Table 10. showing sustainability plan

\begin{tabular}{|c|c|c|}
\hline Sustainability Factor & $\begin{array}{l}\text { Sustainability } \\
\text { Objective }\end{array}$ & Sustainability Action \\
\hline $\begin{array}{l}\text { Integrate project into the } \\
\text { existing system. }\end{array}$ & $\begin{array}{l}\text { Integrate the goals of } \\
\text { the project to goals of } \\
\text { the hospital. }\end{array}$ & $\begin{array}{l}\text { Integrate health promotion activities into the } \\
\text { hospital structure by including roles and } \\
\text { responsibilities of Health promotion activities into } \\
\text { their job description for existing staff. }\end{array}$ \\
\hline $\begin{array}{l}\text { Mobilize resources required to } \\
\text { sustain project with multiple } \\
\text { project sources }\end{array}$ & $\begin{array}{l}\text { Helps to evaluate } \\
\text { project effectiveness } \\
\text { and results } \\
\text { disseminated to } \\
\text { community. }\end{array}$ & $\begin{array}{l}\text { Evaluation plan is designed to assess the impact of } \\
\text { sustainability strategies and Regular meetings to } \\
\text { disseminate results. To ensure continuity. }\end{array}$ \\
\hline $\begin{array}{l}\text { Management openness to } \\
\text { new ideas and readiness to } \\
\text { take risk to increase projects } \\
\text { chances of surviving. }\end{array}$ & $\begin{array}{l}\text { Endorse and support } \\
\text { by the hospital } \\
\text { management }\end{array}$ & $\begin{array}{l}\text { Assess leadership support and implement change } \\
\text { process needed. }\end{array}$ \\
\hline Ensure community support. & $\begin{array}{l}\text { Develop community } \\
\text { support and } \\
\text { ownership. }\end{array}$ & $\begin{array}{l}\text { Encourage cooperation among hospital } \\
\text { community and engage them in project } \\
\text { implementation/evaluation }\end{array}$ \\
\hline $\begin{array}{l}\text { Staff training on health } \\
\text { promotion }\end{array}$ & $\begin{array}{l}\text { Provide staff and } \\
\text { community training } \\
\text { regularly }\end{array}$ & Regular staff training on health promotion. \\
\hline
\end{tabular}

\section{Conclusion}

Following the research findings, the principal investigator found that poor waste management a major problem in Makerere university hospital. The researcher has collaborated with the hospital community to address the challenge of poor waste management, positive change began to manifest hence improving sanitation and health in general.

Greater efforts must be made at the beginning of the activity to bring everybody on board to support the project. Incorporating support staff in all project stages helps them to appreciate the project and in turn participate more actively. The hospital management can support the intervention to improve waste handling however they only need to be stimulated to prioritize it.

\section{Recommendations}

- The hospital should organize more capacitybuilding programs on waste management to equip the staff with adequate skills, knowledge, and ability to handle issues related to health care wastes.

- The hospital should always collaborate with the division health inspector to help them always in proper waste management approaches.

- Further research on strategies being employed by government and elsewhere to cope up with the challenges of health care wastes.

\section{Self-evaluation}

1) The research project was good and the implementation process of the project was successful as the research project used several Ottawa action areas.

2) The research has enabled, mediated and advocated for change in the hospital thereby creating a healthy and friendly community through the availability of dustbins, bin liners, temporary waste storage sites establishment, and supportive environment for sanitation improvement.

3) It has strengthened community action by basically working together to ensure and promote health awareness to improve health determinants for example improving the social and physical environment of the Hospital.

4) Lastly, this research project also helped to build personal skills through providing awareness and information on health and enhancing life skills and knowledge on health and dangers of lack of this knowledge.

\section{Acknowledgment}

I would like to thank the almighty God for his grace, wisdom, and protection he has given me throughout my entire life. 
Special thanks to the family of Mr. and Mrs. Kagambo Solomon for nurturing and sponsoring my academic journey.

Not forgetting to appreciate my supervisor for the support, guidance, encouragement, and mentorship.

Finally, I thank the Makerere University Hospital community for all the support rendered to me during the research exercise.

LIST OF ABBREVIATIONS/ACRONYMS:

WHO World Health Organization

UNDS Uganda National Demographic Surveys

HCWM Health Care Waste Management

KCCA Kampala Capital City Authority

ILO International Labour organisation

MD Medical Director

PPE Personal Protective Equipment

FGD Focus Group Discussion

SMC Safe Male Circumcision

SOPs Standard Operating Procedures

CPD Continuous Professional Development

CME Continuous Medical Education

IEC Information Education and Communication

\section{References:}

1. Helga G. (2012). Helga Gomez's Action Research Journeys.

2. Meyer J. (2000). Qualitative research in health care. Using qualitative methods in health related action research. BMJ (Clinical research ed.), 320(7228), 178-181.

3. Parkin. $P$ (2009). Managing Change in Healthcare: Using Action Research. DOl:http://dx.doi.org/ 10.4135/9781446269350

4. Rawlance Ndejjo, Geofrey Musinguzi, Xiaozhong Yu, Esther Buregyeya, David Musoke, JiaSheng Wang, Abdullah Ali Halage, Christopher Whalen, William Bazeyo, Phillip Williams, John Ssempebwa, "Occupational Health Hazards among Healthcare Workers in Kampala, Uganda", Journal of Environmental and Public Health, vol. 2015, Article ID 913741, 9 pages, 2015. https://doi.org/10.11 55/2015/913741

5. Reason, P., \& Bradbury, H. (Eds.). (2001). Handbook of action research: Participative inquiry and practice. London: Sage Publications

6. Sankaran, S. \& Dick, B. (2015). Linking theory and practice in project management research using action-oriented methods, in Pasian, B. \& Smit, K. (eds.) Methods, Designs and Practices for Research into Project Management, Gower, Aldershot, U.K., 211-224.
7. Whitelaw, S., Beattie, A., Balogh, R. and Watson, J. (2003) A Review of the Nature of Action Research. Cardiff: Welsh Assembly Government.

8. World Health Organization (2014), second edition Safe Management of Wastes from Health-care Activities

9. World Health Organization (2018). Health-Care Waste. https://www.who.int/news-room/fact-shee ts/detail/health-care-waste 